Çukurova Üniversitesi Mühendislik Mimarlık Fakültesi Dergisi, 29(1), 71-80 ss., Haziran 2014

Çukurova University Journal of the Faculty of Engineering and Architecture, 29(1), pp. 71-80, June 2014

\title{
Dolusavak Akımının Farklı Türbülans Kapatma Modelleri ile Sayısal Hesabı
}

\author{
Veysel GÜMÜŞ ${ }^{1 *}$, M. Salih KIRKGÖZ ${ }^{1}$ \\ ${ }^{1}$ Ç. Ü., Mühendislik-Mimarlık Fakültesi, Inşaat Mühendisliği Bölümü, Adana
}

\section{Özet}

Laboratuvardaki bir dolusavak modelindeki akımda hızlar ve su yüzü profili ölçülmüştür. Deneyle aynı özelliklerdeki akımı idare eden temel denklemler Sonlu Hacimler yöntemi ile sayısal olarak çözülmüştür.

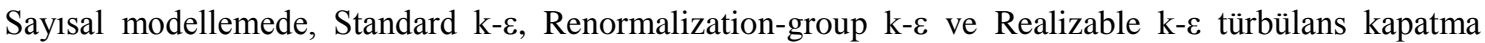
modelleri kullanılmıştır. Sayısal model bulgularının doğrulanmasına yönelik olarak deneysel bulgularla yapılan karşılaştırmalar, Renormalization-group k- $\varepsilon$ ve Realizable k- $\varepsilon$ türbülans modellerinden elde edilen sayısal bulguların birbirlerine çok yakın, ve her iki modelin de hız alanı ve su yüzü profilinin hesaplanmasında Standard k- $\varepsilon$ modeline göre daha başarılı olduğunu göstermiştir.

Anahtar Kelimeler: Dolusavak, hız profili, VOF, Türbülans kapatma modelleri, Sayısal hesaplama

\section{Numerical Analysis of Spillway Flow Using Different Turbulence Closure Models}

\begin{abstract}
Velocity field and free surface profile of flow over a spillway is measured in a laboratory channel. The governing equations are numerically solved using Finite Volume method for the flow having the same conditions with experiment. In the numerical simulation of the flow, Standard k- $\varepsilon$, Renormalization-group $\mathrm{k}-\varepsilon$ and Realizable $\mathrm{k}-\varepsilon$ turbulence closure models are employed. Experimental validations of the computations show that the numerical results from the Renormalization-group k- $\varepsilon$ and Realizable k- $\varepsilon$ turbulence model are very close to each other, and they are both more successful compared to the Standard k- $\varepsilon$ turbulence model, in predicting the velocity field and free surface of the flow.
\end{abstract}

Keywords: Spillway, Velocity field, VOF, Turbulence closure models, Numerical analysis

\footnotetext{
* Yazışmaların yapılacağı yazar: Veysel GÜMÜŞ, Ç.Ü. Mühendislik Mimarlık Fakültesi, İnşaat Mühendisliği Bölümü, Adana.vgumus@cu.edu.tr
} 


\section{GíRiş}

Barajlar, su kaynaklarının geliştirilmesi kapsamında inșa edilen ve ülke kalkınmasına büyük katkılar sağlayan önemli mühendislik yapılarıdır. Dolusavaklar, baraj haznesine gelen taşkın sularını güvenli bir şekilde baraj mansabına aktarmaya yarayan baraj elemanlarıdır. Yeterli kapasiteye sahip bir dolusavak sistemi ve sonunda daha hızlı, ekonomik ve güvenli hesaplama yöntemlerine ihtiyaç duyulduğu söylenebilir.

Günümüzde, Hesaplamalı Akışkanlar Dinamiği (Computational Fluid Dynamics-CFD) bağlamında geliştirilen sayısal çözüm tekniklerinin kullanımıyla, yapılar ile etkileşimleri sırasında ortaya çıkan karmaşık akımların daha hızlı ve güvenilir bir şekilde analizi mümkün olup, bu sayede tasarım amaçlı alternatif çözümlerin hızlı ve ekonomik şekilde gerçekleştirilip yorumlanmasında önemli avantajlar sağlanmış bulunmaktadır [1-6]. Bu bakımdan sayısal model deneyleri, inşaat mühendisliği uygulamalarına konu olan su yapılarının tasarımına da önemli kolaylıklar getirmiş olup bu yöntemler giderek daha yaygın şekilde kullanılmaktadır.

$\mathrm{Bu}$ çalışmada, bir laboratuvar dolusavak modelinden elde edilen deneysel bulgular, aynı geometriye sahip modelin sayısal yöntemlerle hesaplanmasından edinilen bulguların doğrulanmasında kullanılmıştır. Dolusavak modeli ile etkileşim halindeki akımı idare eden temel denklemler, sonlu hacimler yöntemine dayalı ANSYS-Fluent paket programı ile sayısal olarak çözülmüştür. Üç farklı türbülans modeli, Standart $k$ - $\varepsilon$ (SKE), Renormalization-group $k-\varepsilon$ (RNG) ve Realizable $k-\varepsilon$ (RKE) modelleri kullanılarak yer alan enerji kırıcı yapının hidrolik tasarımı, deneysel verilere dayalı geleneksel yöntemlerle başarılı bir şekilde yapılmaktadır. Tasarım amaçlı çalışmalar, gerektiğinde, fiziksel model deneyleriyle de desteklenmektedir. Ancak, bu tür çalışmalar zaman alıcı olduğu gibi proje maliyetini de olumsuz yönde etkileyebilmektedir. Dolayısıyla, dolusavak tasarımında performans belirleyici nitelikte akımda hız alanının sayısal çözümü yapılmıştır. $\mathrm{Su}$ yüzü profilinin hesaplanmasında VOF yöntemi kullanılmıștır. Sayısal hesaplamalardan elde edilen su yüzü profili ve çeşitli kesitlerdeki akım hız profilleri, deneysel ölçümlerler karşılaştırılmış ve kullanılan türbülans modellerinin hesaplamadaki başarısı tartışılmıştır.

\section{MATERYAL VE YÖNTEM}

\subsection{Deneyler}

Deneyler, Güzel [7] tarafından, İnşaat Mühendisliği Hidrolik Laboratuvarında bulunan ve boyutları Şekil 1'de görülen yuvarlak başlıklı bir dolusavak modelinde yapılmıştır. Akım hızları lazer anemometresi ile ölçülmüştür. Şekilde görüldüğü gibi, savağın memba yüzünün eğim açısı $\alpha=32^{\circ}$, tabanı hidrolik cilalı kabul edilen cam duvarlı kanalın uzunluğu $1.8 \mathrm{~m}$, genişliği $0.2 \mathrm{~m}$ ve yüksekliği 0.2 m'dir. Deneyde kullanılan akımın debisi $Q=0.0106 \mathrm{~m}^{3} / \mathrm{s}$ olarak ölçülmüştür. Sayısal hesaplama bölgesinde kullanılan $\mathrm{x}, \mathrm{y}$ yatay ve düşey eksen takımının yanı sıra, şüt kanalındaki bulgular, şekil üzerinde gösterilen kanal doğrultusu ve normalini esas alan $\mathrm{s}, \mathrm{n}$ eksen takımına göre değerlendirilmiştir.

\subsection{Temel Denklemler}

İncelenen dolusavak akımı düzenli, iki-boyutlu, sıkışmayan, türbülanslı bir serbest yüzeyli akımdır. Akımı idare eden temel denklemler, kütlenin korunumu ve momentumun korunumu (Reynoldsortalamalı Navier-Stokes denklemleri), aşağıdaki gibidir:

$$
\frac{\partial \bar{u}_{i}}{\partial x_{i}}=0
$$

$\rho\left(\frac{\partial \bar{u}_{i}}{\partial t}+\bar{u}_{j} \frac{\partial \bar{u}_{i}}{\partial x_{j}}\right)=\rho g_{i}-\frac{\partial \bar{p}}{\partial x_{i}}+\mu \frac{\partial^{2} \bar{u}_{i}}{\partial x_{j}^{2}}+\frac{\partial \tau_{i j}}{\partial x_{j}}$

(1) ve (2) denklemlerinde $u_{i}, x_{i}$ doğrultusundaki hız bileşeni $g_{i}$ yer çekimi ivmesi, $p$ basınç, $\mu$ dinamik viskozite, $\rho$ akışkan yoğunluğu ve $\tau_{i j}$ türbülans (Reynolds) gerilmeleridir. Bu çalışmaya konu olan 


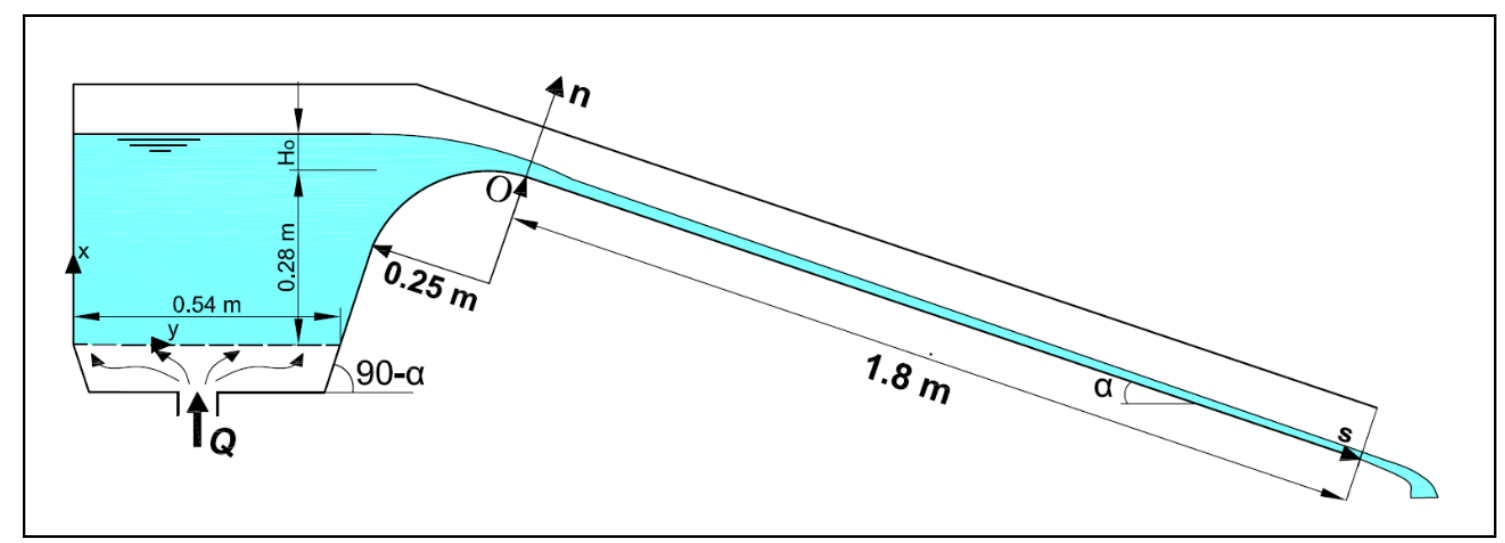

Şekil 1. Deney düzeneği

2-boyutlu akımı idare eden yukarıdaki 3 adet denklem 6 adet bilinmeyen içermektedir (iki hız bileşeni $\bar{u}_{i}$, basınç $\bar{p}$ ve üç bağımsız Reynolds gerilmesi $\left.-\rho \overline{u_{i}^{\prime} u_{j}^{\prime}}\right)$. Böylece, denklem sisteminin çözülebilmesi için türbülans gerilmelerinin tanımlanmasına ihtiyaç duyulmaktadır. Bu sorun, yukarıdaki zamansal-ortalama denklemlerin sayısal hesaplama sürecinde, denklemlerde yer alan türbülans gerilmelerinin türbülans kapatma modelleri kullanılarak çözülmesini gerektirmektedir. Türbülans viskozitesinin doğrusal tanımlanmasını esas alan Boussinesq yaklaşımına göre (2) denklemindeki türbülans kayma gerilmeleri bünye denklemi ile, sıkışmayan akımlar için, aşağıdaki gibi verilmiştir:

$$
\tau_{i j}=-\rho \overline{u_{i}^{\prime} u_{j}^{\prime}}=\mu_{t}\left(\frac{\partial \bar{u}_{i}}{\partial x_{j}}+\frac{\partial \bar{u}_{j}}{\partial x_{i}}\right)-\frac{2}{3} \rho k \delta_{i j}
$$

burada $u_{i}^{\prime}$ ve $u_{j}^{\prime}$ yatay ve düşey türbülans hız sapınçları, $\mu_{t}$ türbülans viskozitesi, $k\left(=\overline{u_{i}^{\prime} u_{i}^{\prime}} / 2\right)$ türbülans kinetik enerjisi ve $\delta_{i j}$ Kronecker deltadır.

\subsection{Türbülans Modelleri}

Denklem (3)'de görülen $\mu_{t}$ türbülans viskozitesinin hesaplanmasında bir çok türbülans modeli geliştirilmiştir. Bu çalışmada, $\mu_{t}^{\prime}$ nin hesabında, $k-\varepsilon$ tabanlı üç türbülans kapatma modeli kullanılmıştır:

- $\quad$ Standart $k-\varepsilon$ (SKE) [8],

- Renormalization Group $k-\varepsilon$ (RNG) [9],

- Realizable $k-\varepsilon$ (RKE) [10]

Bu modeller aşağıda kısaca açıklanmıştır.

\section{SKE Türbülans Modeli}

$\mathrm{Bu}$ model ile türbülans viskozitesi $\mu_{t}$, türbülans kinetik enerjisi, $k$, ve onun kayıp oranına, $\varepsilon$, bağlı olarak aşağıdaki gibi ifade edilmektedir:

$$
\mu_{t}=\rho C_{\mu} \frac{k^{2}}{\varepsilon}
$$

$\frac{\partial(\rho k)}{\partial t}+\bar{u}_{j} \frac{\partial(\rho k)}{\partial x_{j}}=\frac{\partial}{\partial x_{j}}\left[\left(\mu+\frac{\mu_{t}}{\sigma_{k}}\right) \frac{\partial k}{\partial x_{j}}\right]+\tau_{i j} \frac{\partial \bar{u}_{i}}{\partial x_{j}}-\rho \varepsilon$

$\frac{\partial(\rho \varepsilon)}{\partial t}+\bar{u}_{j} \frac{\partial(\rho \varepsilon)}{\partial x_{j}}=\frac{\partial}{\partial x_{j}}\left[\left(\mu+\frac{\mu_{t}}{\sigma_{\varepsilon}}\right) \frac{\partial \varepsilon}{\partial x_{j}}\right]+C_{1 \varepsilon} \frac{\varepsilon}{k} \tau_{i j} \frac{\partial \bar{u}_{i}}{\partial x_{j}}-C_{2 \varepsilon} \rho \frac{\varepsilon^{2}}{k}$

$C_{\mu}$ boyutsuz model sabitidir. (4) denklemindeki $k$ ve $\varepsilon$ değerlerinin bulunması için iki adet kısmi 
diferansiyel transport denkleminin çözülmesi gerekmektedir, bunlar: SKE model sabitleri, $C_{\mu}=0.09, \quad \sigma_{k}=1.0, \quad \sigma_{\varepsilon}=1.3, \quad C_{1 \varepsilon}=1.44, \quad C_{2 \varepsilon}=1.92$ değerlerini almaktadır [8].

\section{RNG Türbülans Modeli}

$\mathrm{Bu}$ modelde $k$-denklemi SKE ile aynı olup $\varepsilon$ denklemi aşağıdaki gibi ilave kaynak terimi içermektedir:

Model sabitleri aşağıdaki gibi verilmiştir:

$C_{\mu}=0.0845$, $\sigma_{k}=\sigma_{\varepsilon}=0.7194$,

$C_{1 \varepsilon}^{*}=C_{1 \varepsilon}-\frac{\eta\left(1-\eta / \eta_{0}\right)}{1+\beta \eta^{3}}, \quad C_{2 \varepsilon}=1.68, C_{1 \varepsilon}=1.42$

$\eta=\left(2 S_{i j} S_{i j}\right)^{1 / 2} \frac{k}{\varepsilon}, \quad S_{i j}=\frac{1}{2}\left(\bar{u}_{i, j}+\bar{u}_{j, i}\right)$,

$\eta_{0}=4.377, \beta=0.012$ (Deneysel)

$S_{i j}$ şekil değiştirme hızı tansörüdür. Görüldüğü gibi (7) denklemi akışkan şekil değiştirmesine bağlı $\eta$ parametresini içermektedir. $\mathrm{Bu}$ ilave parametre sayesinde RNG modelinin ivmelenen, şiddetli eğriselliğe maruz, sınır tabakasının ayrıldığı, ikincil akımlar ve durma noktasının mevcut olduğu akımlarda SKE modeline göre daha gerçekçi sonuçlar verdiği iddia edilmiştir [9].

$$
\frac{\partial(\rho \varepsilon)}{\partial t}+\bar{u}_{j} \frac{\partial(\rho \varepsilon)}{\partial x_{j}}=\frac{\partial}{\partial x_{j}}\left[\left(\mu+\frac{\mu_{t}}{\sigma_{\varepsilon}}\right) \frac{\partial \varepsilon}{\partial x_{j}}\right]+C_{1 \varepsilon}^{*} \frac{\varepsilon}{k} \tau_{i j} \frac{\partial \bar{u}_{i}}{\partial x_{j}}-C_{2 \varepsilon} \rho \frac{\varepsilon^{2}}{k}
$$

\section{RKE Türbülans Modeli}

Akım alanındaki yüksek şekil değiştirme hızlarının ve sınır tabakası ayrılmasının mevcut olduğu karmaşık akım durumlarında SKE türbülans modeli üzerinde, performans artırıcı olarak RKE modeli adı altında şu iyileştirmeler yapılmıştır: (a) türbülans viskozitesi, $\mu_{t}$, ifadesinde, sabit yerine değişken $C_{\mu}$ terimi kullanılarak SKE modelindeki katı yüzeye dik şekil değiştirme bileşenlerinin değeri küçültülmüş, ve (b) $\varepsilon$ transport denkleminde yerel şekil değiştirme hızını esas alan farklı bir kaynak terimi kullanılmıştır. Shih ve diğ., [10] $C_{\mu}^{*}$ için aşağıdaki formülü vermişlerdir:

$$
C_{\mu}^{*}=\frac{1}{A_{o}+A_{s} \frac{U^{*} k}{\varepsilon}}
$$

Burada, $\quad A_{o}=4, \quad A_{s}=\sqrt{6} \cos \phi$, $\phi=\frac{1}{3} \arccos (\sqrt{6} W), W=\frac{S_{i j} S_{j k} S_{k i}}{\tilde{S}^{3}}, \tilde{S}=\sqrt{S_{i j} S_{i j}}$,

$U^{*}=\sqrt{S_{i j} S_{i j}+\tilde{\Omega}_{i j} \tilde{\Omega}_{i j}}, \tilde{\Omega}_{i j}=\Omega_{i j}-2 \varepsilon_{i j k} \omega_{k}^{*}$,

$\Omega_{i j}=\bar{\Omega}_{i j}-\varepsilon_{i j k} \omega_{k}^{*}, \Omega_{i j}=\frac{1}{2}\left(\bar{u}_{i, j}-\bar{u}_{j, i}\right)$

$\bar{\Omega}_{i j}, \omega_{k}^{*}$ açısal hızı ile dönen eksen takımına göre

ölçülen ortalama rotasyon hızı tansörüdür. $\varepsilon$ denklemi aşağıdaki gibi ifade edilmiştir:

$$
\frac{\partial(\rho \varepsilon)}{\partial t}+\bar{u}_{j} \frac{\partial(\rho \varepsilon)}{\partial x_{j}}=\frac{\partial}{\partial x_{j}}\left[\left(\mu+\frac{\mu_{t}}{\sigma_{\varepsilon}}\right) \frac{\partial \varepsilon}{\partial x_{j}}\right]+\rho C_{1} S \varepsilon-\rho C_{2} \frac{\varepsilon^{2}}{k+\sqrt{v \varepsilon}}
$$

\subsection{Akışkan Hacimleri Yöntemi (VOF)}

$\mathrm{Bu}$ çalışmada su-hava ara kesitinin hesabında akışkan hacimleri (Volume of Fluid-VOF) yöntemi kullanılmıştır [11]. VOF yöntemi, hesaplama ağındaki eleman hacimlerinin boş, kısmen dolu ya da tamamen su ile dolu olduğunu belirlemede kullanılmaktadır. Hacimsel doluluk oranını temsilen, $F=1$ için ağ elemanı tam dolu, $F=0$ için boş (hava ile dolu) ve $0>F>1$ için su ile kısmen dolu olmaktadır.

Akışkan Hacimleri Yöntemi ile serbest su yüzünün hesaplanmasında "Geo-Reconstruct" yaklaşımı kullanılmıştır [12]. Bu yaklaşıma göre, öncelikle, kısmen dolu her bir hücrenin, doluluk oranı ve onun türevleri ile ilgili bilgilere dayanılarak, havasu doğrusal ara yüzünün hücre ağırlık merkezine göre yeri belirlenir.

Bir sonraki adımda, hesaplanmış doğrusal ara yüzün yeri ve eleman yüzeylerinde hesaplanmış normal ve teğetsel hız bilgileri kullanılarak her bir eleman yüzeyinden taşınan akışkan miktarları hesaplanır. Son olarak, bir önceki adımda hesaplanan akışkan miktarları göz önüne alınarak, süreklilik denklemi ile her bir hücrenin hacimsel doluluk oranı hesaplanır. 


\subsection{Sınır Şartları}

Şekil 2, dolusavak üzerinden geçen açık kanal akımının sayısal modeli için kullanılan çözüm bölgesi ve sınır şartlarını göstermektedir. $x, y$ koordinat sisteminin orijini, çözüm bölgesinin sol alt köşesi olarak alınarak, şekilde verilen çözüm bölgesi beş bölgeye ayrilmış ve çözüm bölgesinin üst sınırı ve çıkış bölgesi sınır şartı $p=0$, kanal tabanında ve savak alt tabanında sifir hiz sinır şartı, yani $u=0, v=0$ olarak tanımlanmıştır. Giriş sınır şartı olarak düşey hız bileşeni $v=0.0987 \mathrm{~m} / \mathrm{s}$ olarak tanımlanırken yatay hız bileşeni $u=0$ olarak alınmıştır. Zamana bağlı çözüm sürecinde, başlangıç şartı olarak, $t=0$ anında boş olan çözüm bölgesinin giriş sınırında VOF yöntemi için $F=1$ alınmıştır.

\subsection{Sayısal Çözüm}

Akımı idare eden (1) ve (2) denklemlerinin, Şekil 3'de görülen sınır şartlarına göre $\bar{u}, \bar{v}$ ve $\bar{p}$ için sayısal çözümü, Sonlu Hacimler yöntemine dayal1 ANSYS-Fluent $^{\circledR}$ v.12.1 paket programı kullanılarak yapılmıştır. Hız-basınç eşleştirmesi için SIMPLE (Semi-implicit method for pressurelinked equations) algoritması [13] kullanılmıştır. $\mathrm{Bu}$ algoritma hız, basınç ve diğer değişkenler için ilk tahmin değerleri ile momentum denklemlerinin çözümünü yapmaktadır. Bulunan değerler ile hız ve basınç düzeltmesi yaparak türbülans modellerindeki transport denklemlerini çözmekte ve sayısal bulgularda yakınsama gerçekleşinceye kadar iterasyona devam etmektedir. Hesaplamalarda tüm değişkenler $(u, v, k, \varepsilon)$ için yakınsama kriteri olarak artık hatanın (residual error) $10^{-5}$ in altına düşmesi şartı aranmıştır. Momentum ve türbülans kinetik enerjisi ifadelerinin ayrıklaştırılması için ikinci mertebe upwind yöntemi kullanılırken, basınç teriminin ayrıklaştırılmasında PRESTO (Pressure staggered option) metodu [14] kullanılmıştır. Ayrıca, zamana bağlı ayrıklaştırmanın gerçekleştirilmesinde, birinci mertebe sonlu farklar kapalı çözüm formülasyonu kullanılmış ve $\Delta t=0.001 \quad \mathrm{~s}$ olarak seçilen her bir zaman adımındaki maksimum iterasyon sayıs1 10 alınmıştır. Kanal tabanında katı sınıra yakın akım bölgesinin modellenmesinde Chen ve Patel [15] tarafından önerilen iki-tabakalı çözümü esas alan ve genişletilmiş iki-tabakalı duvar-yakını modellemesi olarak anılan yöntem kullanılmıştır [12].

\subsection{Hesaplama Ağının Tasarımı}

Hesaplama ağının tasarımı için çözüm bölgesi, Şekil 3 'te görüldüğü gibi beş alt bölgeye ayrılmış ve ağ yapısının çözüm üzerindeki etkisinin incelenmesinde kullanılan ayrıklaştırma hatasının tespiti için üç farklı hesaplama ağ oluşturulmuştur. Oluşturulan ağ yapısının her bir alt bölgesindeki eleman sayısı yaklaşık olarak \%50 ve $\% 75$ oranında artırılmak suretiyle dörtgen elemanlardan oluşan 3 farklı yoğunluğa sahip hesaplama ağları kullanılmıştır. Çizelge 1'de, sayısal hesaplamalarda kullanılan üç farklı ă̆ yapısı için eleman sayıları verilmiştir. Sayısal çözüm alanındaki ağ yapısının yeterli sıklıkta olup olmadığı, bir başka ifadeyle ağ yapısından bağımsız sayısal çözümler elde etmek amacıyla ele alınan üçlü ağ sisteminde yapılan sıklaştırmanın uygunluğu, GCI (Grid convergence index-A $\breve{g}$ yakınsama indeksi) yöntemiyle test edilmiştir [16-17]. Üç farklı kesitte $(\mathrm{s}=0,04 \mathrm{~m}, 0,74 \mathrm{~m}$ ve $1,36 \mathrm{~m})$ yapılan ağ yakınsama indeksi değerlerinin $\% 0,0001$ ile \% 1.3 değerleri arasında değiştiği görülmüștür. Böylece, A $\breve{g} 3$ sistemiyle, akım hızlarındaki hataların kabul edilebilir değer olan 2 den küçük olduğu görülmüş ve hesaplama hassasiyetinin a ̆ yoğunluğundan bağımsızlaştığ1 kanaatine varılmıştır.

Ağ 3 kullanılarak üç farklı türbülans modeli ile yapılan hesaplamalarda, tabandaki birinci ağ elemanı için hesaplanan $y^{+}\left(=u_{*} y / v\right)$ değerinin IV ve $\mathrm{V}$ bölgelerindeki en büyük değerleri Çizelge 1'de görülmektedir. Burada $u_{*}\left(=\left(\tau_{\mathrm{o}} / \rho\right)^{1 / 2}\right)$ kayma hızı, $y$ birinci ağ elemanının tabana dik boyutu ve $v$ kinematik viskozitedir.

Çizelgede görüldüğü gibi $y^{+}$nın en büyük değeri, şüt kanalının sonunda oluşmakta ve 7'yi aşmamaktadır. Yani katı sınırdaki birinci ağ elemanı, geçmişteki deneysel verilerin göstergeleri dikkate alındığında [18], tüm çözüm 


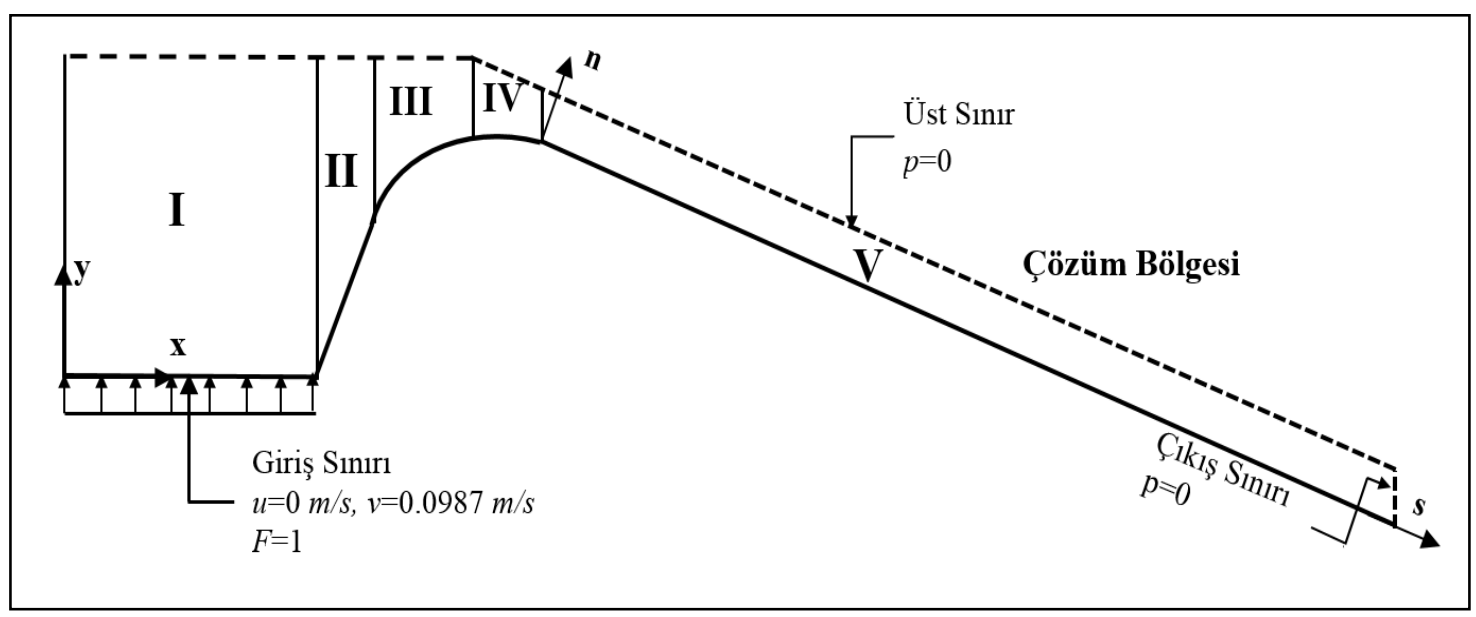

Şekil 2. Sayısal çözüm bölgesi ve sınır şartları

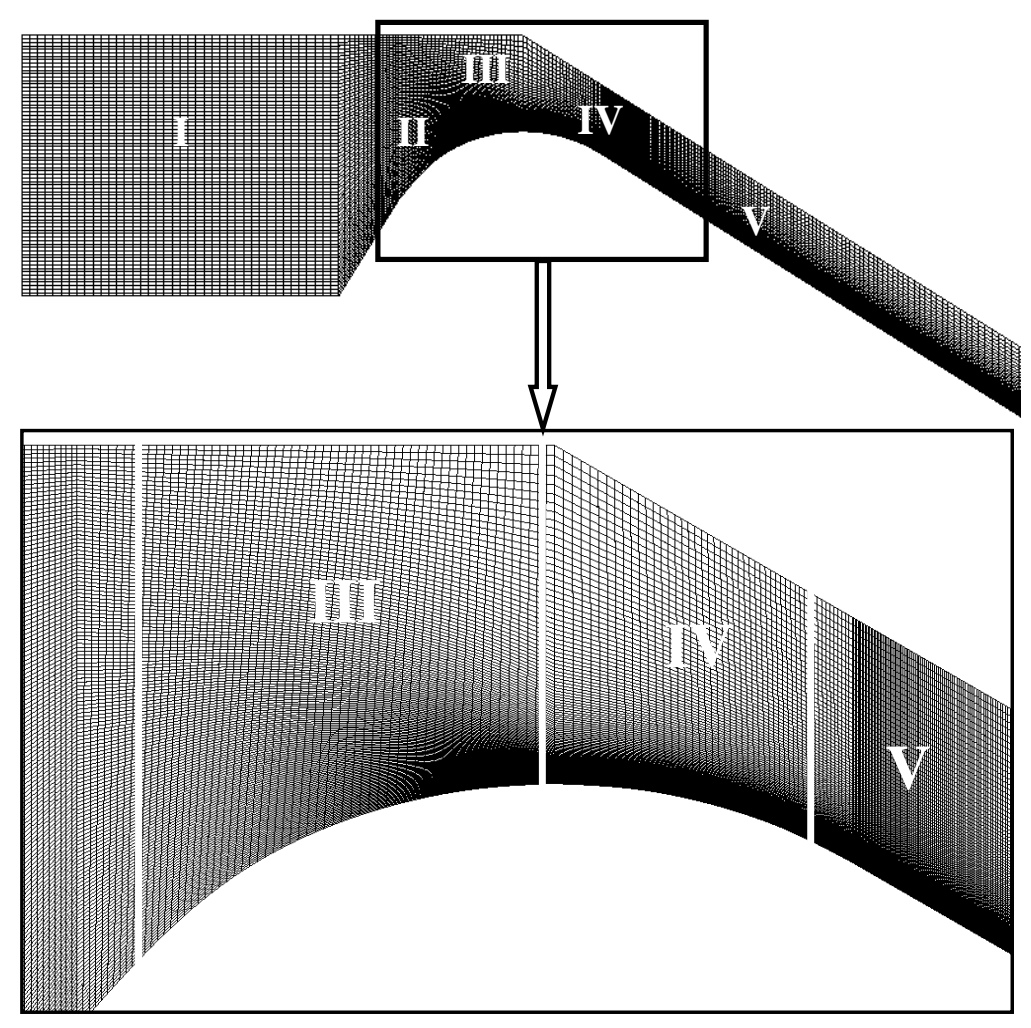

Şekil 3. Sayısal modelde kullanılan hesaplama ağı 
Çizelge 1. Farklı yoğunluktaki hesaplama ağlarında bölgesel eleman sayıları

\begin{tabular}{|c|c|c|c|c|c|}
\hline Bölge & $\mathbf{A \breve { g } 1}$ & $\mathbf{A \breve { g } 2}$ & $\mathbf{A \breve { g } 3}$ & $\begin{array}{c}\text { Min } \\
\mathbf{y +}\end{array}$ & $\begin{array}{c}\text { Mak } \\
\mathbf{y}^{+}\end{array}$ \\
\hline I & $40 \times 75$ & $60 \times 100$ & $80 \times 150$ & - & - \\
\hline II & $15 \times 75$ & $20 \times 100$ & $30 \times 150$ & - & - \\
\hline III & $30 \times 75$ & $45 \times 100$ & $60 \times 150$ & - & - \\
\hline IV & $25 \times 75$ & $35 \times 100$ & $50 \times 150$ & 3 & 3.75 \\
\hline V & $200 \times 75$ & $300 \times 100$ & $400 \times 150$ & 2.8 & 6.95 \\
\hline
\end{tabular}

bölgesinde viskoz alt tabakanın içerisinde yer almaktadir.

\section{BULGULAR VE TARTIŞMA}

\subsection{Deneysel ve Hesaplanan Hız Profilleri}

$k$ - $\varepsilon$ tabanlı türbülans modellerinin doğrulanması bağlamında hesaplanan ve deneysel hız profillerinin niceliksel karşılaştırılmasında Ortalama Karesel Hata (OKH) ölçüt olarak kullanılmıștır:

$$
\mathrm{OKH}=\frac{1}{N} \sum_{n=1}^{N}\left(v_{d}-v_{h}\right)^{2}
$$

Burada, $v_{d}$ ve $v_{h}$ sirasiyla deneysel ve hesaplanan hız değerini, $N$ hız profilinde kullanılan nokta sayısını göstermektedir.

Çizelge 2'te, bu çalışmada kullanılan türbülans modelleriyle farklı kesitlerde hesaplanan hiz profilleri için $\mathrm{OKH}$ değerleri verilmiştir. Çizelgedaki değerlerden, kullanılan türbülans modellerinden RNG ve RKE nin tüm kesitlerde SKE türbülans modeline göre daha başarılı olduğu, RNG ve RKE türbülans modellerinin ise genel olarak birbirine yakın sonuçlar verdiği görülmekle birlikte, RKE modelinin, az da olsa daha başarılı olduğu söylenebilir.

Şekil 4'te, şüt kanalı üzerinde deneysel olarak ölçülen hız profillerinin, üç farklı türbülans modeli ile hesaplanan profillerin grafiksel olarak karşılaştırılması sunulmuştur. Şekillerden, RNG ve
Çizelge 2. Türbülans modelleri ile hesaplanan hız profilleri için $\mathrm{OKH}$ değerleri,

\begin{tabular}{|c|c|c|c|}
\hline \multirow{2}{*}{$\mathbf{s}(\mathbf{m})$} & \multicolumn{3}{|c|}{ OKH $\left(\mathbf{c m}^{\mathbf{2}} / \mathbf{s}^{\mathbf{2}}\right)$} \\
\cline { 2 - 4 } & SKE & RNG & RKE \\
\hline $\mathbf{0 . 0 4}$ & 30 & 12 & 10 \\
\hline $\mathbf{0 . 1 4}$ & 21 & 9 & 8 \\
\hline $\mathbf{0 . 2 4}$ & 29 & 9 & 8 \\
\hline $\mathbf{0 . 3 4}$ & 37 & 13 & 12 \\
\hline $\mathbf{0 . 4 4}$ & 39 & 13 & 13 \\
\hline $\mathbf{0 . 5 4}$ & 41 & 22 & 22 \\
\hline $\mathbf{0 . 7 4}$ & 65 & 32 & 32 \\
\hline $\mathbf{0 . 9 1}$ & 86 & 28 & 27 \\
\hline $\mathbf{1 . 0 6}$ & 100 & 30 & 29 \\
\hline $\mathbf{1 . 2 1}$ & 126 & 34 & 32 \\
\hline $\mathbf{1 . 3 6}$ & 114 & 52 & 50 \\
\hline $\mathbf{1 . 5 1}$ & 161 & 96 & 91 \\
\hline Ortalama & $71^{3}$ & $29^{2}$ & $\mathbf{2 8}$ \\
\hline
\end{tabular}

RKE türbülans modelleri ile hesaplanan hız profillerinin birbirleriyle ve deneylerle uyumlu olduğu görülmektedir. Ancak SKE türbülans modeli ile hesaplanan hiz profillerinin diğer iki modele göre, deneysel profillerle uyumunun daha zayıf olduğu görülmektedir.

\subsection{Deneysel ve Hesaplanan Su Yüzü Profilleri}

Şekil 5'de, üç türbülans modeline ait hesaplanan su yüzü profillerinin deneyler ile karşılaştırılması görülmektedir. Şekilde görüldüğü gibi, RNG ve RKE türbülans modellerinin kullanıldığı sayısal hesaplamalardan elde edilen su yüzü profilleri ölçülen su yüzü profili ile daha uyumludur.

\section{SONUÇ}

Dolusavak üzerinden geçen serbest yüzeyli akımın sayısal modellenmesinde akımı idare eden denklemler, sonlu hacimler yöntemine dayalı ANSYS-Fluent programı ile çözülmüştür. SKE, RNG ve RKE türbülans modelleri kullanılarak yapılan sayısal hesaplamalarda serbest su yüzünün profili, VOF yöntemi ile belirlenmiştir. Sayısal modellemede kullanılan ağ yapısının, hesaplar üzerindeki etkisini incelemek üzere, A $\breve{g}$ Yakınsama İndeksi (GCI) kullanılmış ve ağ yoğunluğuna bağlı hesaplama hatasının \% 2'nin 


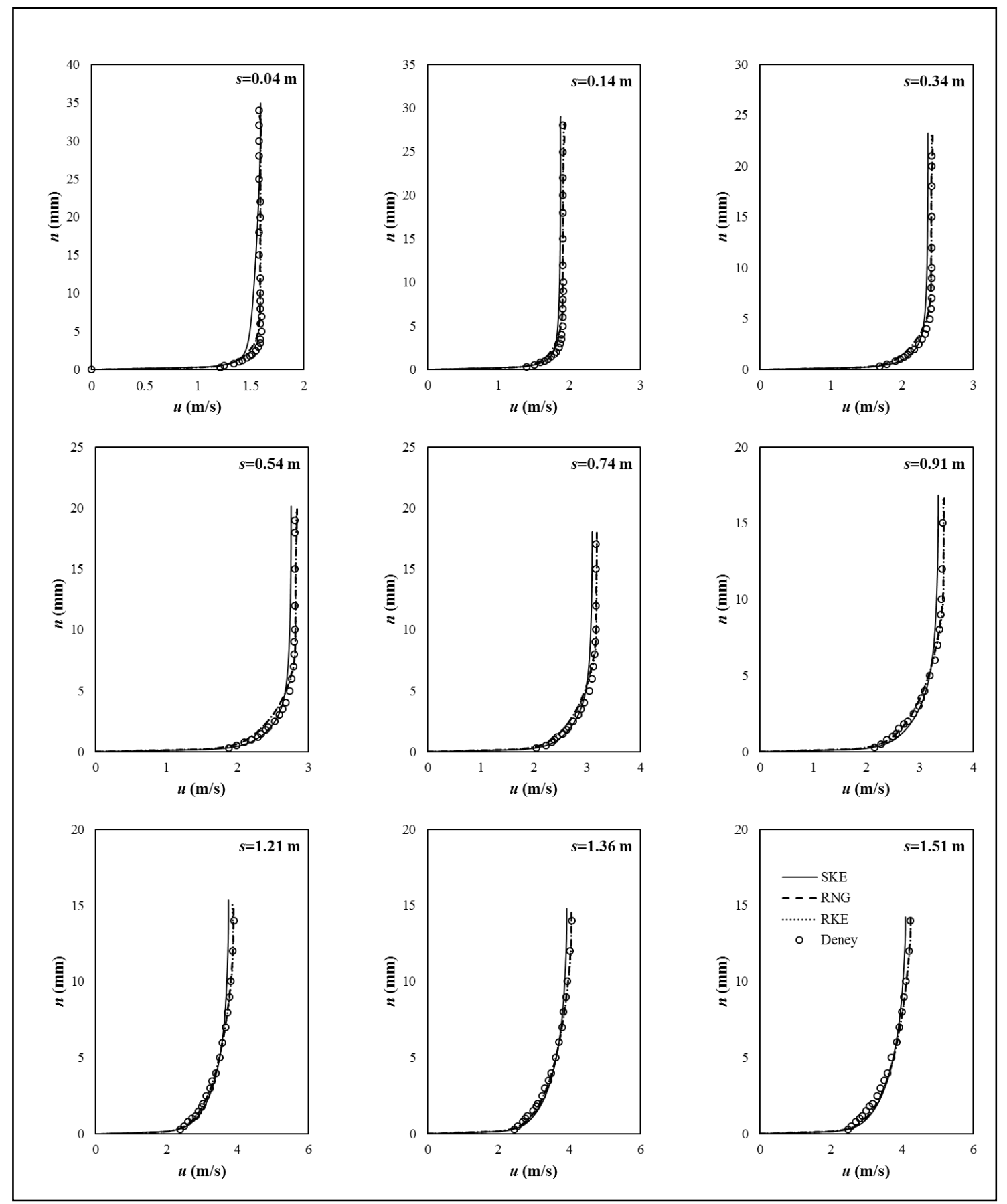

Şekil 4. Deneysel ve sayısal hız profilleri 


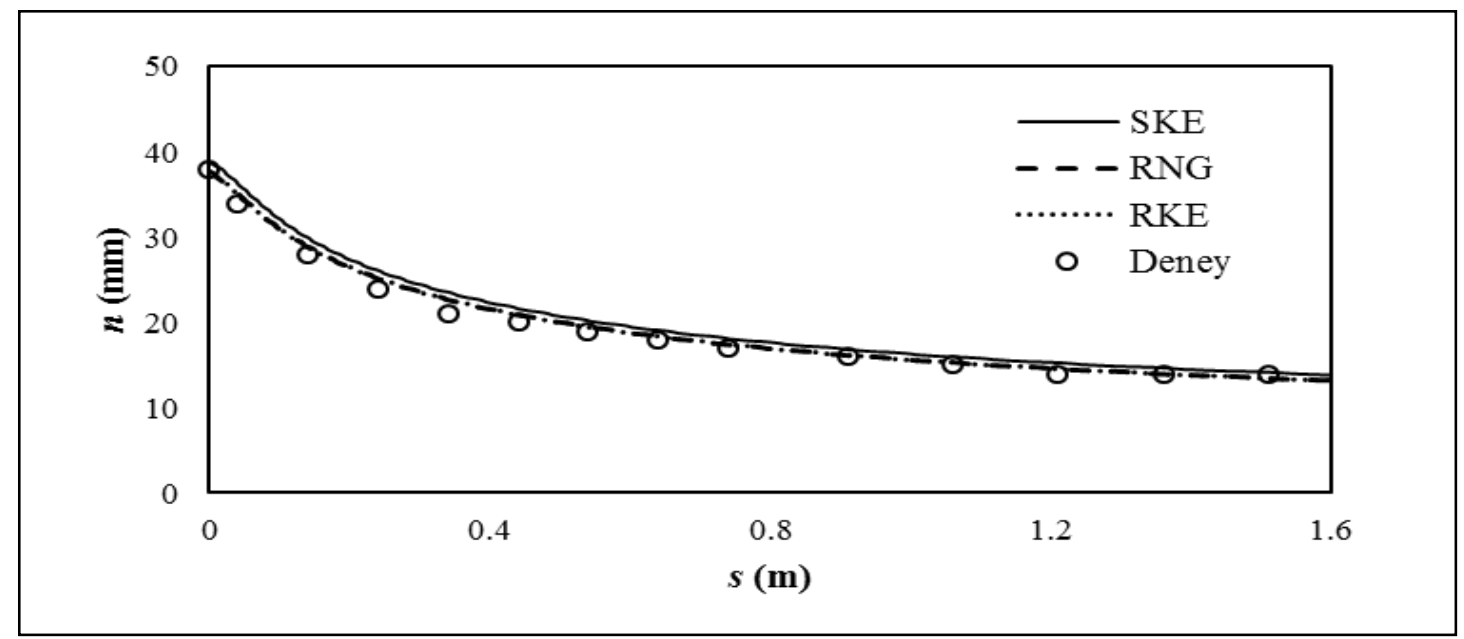

Şekil 5. Deneysel ve sayısal su yüzü profilleri

altında kaldığı görülmüştür. Hız profilleri ve şüt kanalındaki su yüzü profilleri için deneysel ve sayısal bulguların karşılaştırılmasından, çalışmaya konu olan akım koşulları bakımından RNG ve RKE türbülans modellerinin SKE modeline göre daha başarılı olduğu görülmüştür. Buna göre, RKE ve RNG türbülans modelleri kullanılarak elde edilen bulguların birbirlerine çok yakın olması nedeniyle, her iki türbülans modelinin de dolusavak akımının sayısal çözümünde ve dolayısıyla dolusavakların hidrolik tasarımında başarılı bir şekilde kullanılabileceği sonucuna varılmıştır.

\section{TEŞEKKÜR}

Bu çalışma MMF2011D3 nolu proje ile Çukurova Üniversitesi, Araştırma Projeleri Birimi tarafından desteklenmiştir, teşekkür ederiz.

\section{KAYNAKLAR}

1. Kırkgöz, M.S., Aköz, M.S. ve Öner, A.A. 2008. "Experimental And Theoretical Analyses of 2D Fows Upstream of Broad-Crested Weirs", Canadian Journal of Civil Engineering, 35(9): 975-986.

2. Aköz, M.S. ve Kirkgöz, M.S. 2009. "Numerical and Experimental Analyses of the
Flow Around a Horizontal Wall-Mounted Circular Cylinder", Transactions of the Canadian Society for Mechanical Engineering, 33(2), 29-55.

3. Aköz, M.S., Kırkgöz, M.S. ve Öner, A.A. 2009. "Experimental and Numerical Modeling of a Sluice Gate Flow", Journal of Hydraulic Research. 47(2), 167-176.

4. Öner A. A, Aköz M. S., Kırkgöz M. S., and Gümüş, V. 2012. "Experimental Validation of Volume of Fluid Method for a Sluice Gate Flow," Advances in Mechanical Engineering, vol. 2012, 10.

5. Soydan N. G., Aköz, M. S., Şimşek, O. ve Gümüş, V. 2012. “Trapez Kesitli Geniş Başlıklı Savak Akımının K-E Tabanlı Türbülans Modelleri ile Sayısal Modellenmesi”, Çukurova Üniversitesi Mühendislik Mimarlık Fakültesi Dergisi, 27(2), ss. 47-58.

6. Kırkgöz, M.S., Gümüş, V., Soydan, N.G., Şimşek, O. ve Aköz, M.S. 2012. "Experimental and Numerical Modeling of Flow over a Gate- Controlled Semi-Cylinder Weir", 10th International Congress on Advances in Civil Engineering, 17-19 October, Ankara, 0184:1-10.

7. Güzel, H. 1991. "Baraj Dolusavak Kanalında Enerji Kaybının İncelenmesi”, Y. Lisans Tezi, Ç.Ü. Fen Bilimleri Enstitüsü. Adana. 
8. Launder B. E. ve Spalding D. B., 1972. "Lectures in Mathematical Models Ofturbulence. Academic Press", London, England.

9. Yakhot, V., Orszag, S.A., Thangam, S., Gatski, T.B. ve Speziale, C.G., 1992. "Development of Turbulence Models for Shear Flows by a Double Expansion Technique", Physics of Fluids A, 4(7), 1510-1520.

10. Shih T.H., Liou W.W., Shabbir A., Yang Z. ve Zhu J, (1995). "A New k- $\varepsilon$ Eddy-Viscosity Model for High Reynolds Number Turbulent Flows - Model Development and Validation", Computers Fluids, 24(3).227-238.

11. Hirt, C. W. ve Nichols, B. D., 1981. "Volume of Fluid (VOF) Method for the Dynamics of Free Boundaries", J. Comput. Phys., 39, pp., 201-225.

12. Ansys Inc., 2012. Release 14.0. www.ansys.com.

13. Patankar, S.V. ve Spalding, D.B., 1972. "A Calculation Procedure for Heat, Mass and Momentum Transfer in Three-Dimensional Parabolic Flows", International Journal of Heat and Mass Transfer, 15, 1787-1806.

14. Patankar, S.V., 1980. Numerical Heat Transfer and Fluid Flow, Hemisphere, Washington.

15. Chen, H.C. ve Patel, V.C., 1988. "Near-Wall Turbulence Models for Complex Flows Including Separation", AIAA journal, 26(6), 641-648.

16. Roache, P.J., 1998. “Verification of Codes and Calculations", AIAA Journal, 36(5), 696702.

17. Çelik, İ.B., Ghia, U., Roache, P.J., Freitas, C.J., Coleman, H. ve Raad, P.E., 2008. "Procedure for Estimation and Reporting of Uncertainty Due to Discretization in CFD applications", ASME Journal of Fluids Engineering, 130(1), 1-4.

18. Kırkgöz, M.S. ve Ardiçlıŏlu, M., 1997. "Velocity Profiles of Developing and Developed Open Channel Flow", Journal of Hydraulic Engineering, 123(12), 1099-1105. 
